\title{
The Role of the Union Health and Safety Committee in Evaluating the Health Hazards of Hospital Workers: A Case Study
}

\author{
Jeanne M. Stellman, ${ }^{*}, 1$ Steven D. Stellman, $\dagger$ Judy Berek, \\ and Arlene Ezraty $\ddagger$ \\ *Division of Occupational Health and Toxicology and + Division of Biostatistics, \\ American Health Foundation, 320 East 43rd Street. New York, New York 10017, and \\ $\$$ District 1199 of the National Union of Hospital and Health Care Employees, \\ 310 West 43rd Street, New York. New York 10036
}

\begin{abstract}
The Union Health and Safety Committee is an important tool for evaluating and reducing job-related health risks among hospital workers. The experience of one such committee which effectively performed this duty at New York University Medical Center has led to a city-wide survey by District 1199 of working conditions and health status among hospital laboratory workers. Results showed a possible association of hepatitis with some job practices and led to constructive suggestions for improving working conditions and reducing disease risk among hospital workers.
\end{abstract}

The Occupational Safety and Health Act of 1970 obligates employers to provide a workplace which is "free from recognized hazards" likely to harm employees and, at the same time, obliges each employee to comply with standards, rules, and regulations which apply to his/her own profession. It goes without saying that, in order to achieve maximum employer-employee cooperation in maintaining a safe and healthful workplace, employees must be fully informed and educated in the potential hazards related to their particular jobs and must therefore develop mechanisms for obtaining this information and, equally important, for applying this knowledge cooperatively to aid management in fulfilling its obligations to provide a safe and healthful workplace.

One mechanism through which employees can exercise their rights and obligations under the law is the health and safety committee. Health and safety committees have been established in many industries, chiefly in workplaces covered by union collective bargaining agreements (1) and, not surprisingly, tend to be prevalent in more hazardous industries. It has also been reported that a hospital employee safety program, when directed by an effective safety committee, can save thousands of dollars in insurance compensation costs (3). The effectiveness of such committees depends strongly on the degree to which the work force at risk is represented, their level of knowledge of their own specific workplace hazards, and the extent to which management recognizes their participation and follows their recommendations.

In this paper we address the specific role that the hospital health and safety committee can play in educating its own members about the health risks to which

\footnotetext{
${ }^{1}$ To whom requests for reprints should be sent.
} 
the hospital workers it represents are exposed and, by means of a case study of one such union, illustrate the potentially positive impact this committee may have on worker health.

\section{HISTORICAL BACKGROUND}

District 1199 of the National Union of Hospital and Health Care Employees represents 70,000 workers in 100 hospitals in New York City. Of these workers $80 \%$ are women. Many different types of workers are included in various bargaining units, such as nurses, orderlies, laboratory technicians, etc. The District 1199 Laboratory Committee, a group that deals with the professional interest of laboratory technicians and technologists, decided in 1972 to focus on problems relating to the handling of specimens from patients with highly infectious disease. During the earliest phases of this discussion one of the committee members contracted hepatitis. For this reason the committee chose to focus on her employer, New York University Medical Center (N.Y.U.).

An Occupational Health Committee was formed to try to deal with what appeared to be an unusual number of cases of hepatitis among their fellow workers. While lack of good records and employee mobility and turnover made estimation of an incidence rate impossible, committee members identified four cases of hepatitis in chemistry laboratory workers within 1 year and an additional 16 cases among employees in the blood gases lab and intensive care units. District 1199 established an important precedent by obtaining Workers's Compensation for those technicians, thus establishing hepatitis as a compensable occupational disease in New York State.

Initial overtures to management were favorably received and resulted in a meeting between District 1199 members and hospital representatives. The District 1199 representatives included its Health Professions Coordinator (Judy Berek) and four 1199 Guild Delegates who worked in various laboratories, including chemistry and pathology; two of these Guild Delegates had had hepatitis. Representing the hospital were its director of laboratories, the head of Employee Health Services, the hospital infectious disease surveyor, the clinical director of biochemistry, a pathologist, and the associate director of laboratories.

Concurrent with the meeting at N.Y.U., the Union's Lab Committee members canvassed their fellow workers and surveyed the laboratories of N.Y.U. and three additional institutions. They managed to identify the following potential problem areas:

Lack of precaution in handling serum specimens;

Pipetting potentially infected samples by mouth;

Failure to sterilize glass pipettes after use;

Infrequent washing of laboratory floors;

Garbage cans overflowing with discarded specimens;

Contamination of lab sinks and fixtures during specimen disposal; and

Uniforms which were difficult to remove for employees' coffee breaks or lunch.

The Laboratory Committee's preliminary findings resulted in a number of specific actions designed to educate other hospital employees and also to correct some of the unhealthful conditions. First, the union vice president on the commit- 
tee prepared a report for the 1199 Delegate Assembly, so that Union-wide policy could be set. Second, a subcommittee volunteered to survey all Union-represented hospital labs to determine safety practices and conditions. Third, the work of the committee was publicized in the Union Newspaper and magazine so that other workers could benefit from the N.Y.U. experience. And fourth, immediate steps for reducing risk of infection to laboratory workers were recommended. These steps covered six areas of specimen collection and handling, as shown in Table 1.

The Laboratory and Safety Subcommittee evaluated the effectiveness of the original questionnaire and developed a formal printed questionnaire to distribute to the union members in 34 hospitals in New York during 1975 and 1976. The purpose of the survey was to acquaint lab workers with potential problems in their own workplaces, to alert them to the concern of their Union, and to demonstrate that it was possible to participate in solving some of these problems. Nearly 700 responses were received, encoded by volunteers from District 1199, and analyzed by the American Health Foundation. Since the respondents were highly motivated and obviously self-selected, the survey results do not represent a sample in any statistical sense. The technicians in institutions where Health and Safety Subcommittee members worked responded at a very high rate. About one-third of all District 1199 lab workers employed in the 34 hospitals surveyed responded.

\section{SURVEY RESULTS}

Of the 696 responses received, $90 \%$ were from technicians, and the remainder were from clerical people or aides. Respondents had worked a median of 6 years in their respective laboratories. One-fifth of the workers represented chemistry labs, 15\% hematology, 15\% general, 13\% microbiology, and lesser percentages from other labs such as cytology and histology. It should be pointed out that some hospitals have highly specialized lab functions, while others group many of these services together. Some workers worked alongside as many as $\mathbf{3 0}$ other employees, but about half worked in laboratories with four or fewer other workers.

Ventilation. Three-hundred and four respondents said a hood was necessary and available for their work. Of these, $23 \%$ said it was not comfortable to work with, $10 \%$ said it was not in good working condition, $15 \%$ were dissatisfied with

TABLE 1

Potential Areas identified as Health Risks to Hospital Employees and Lab Workers

1. Identification of patients with communicable diseases Worker contact with patients

2. Collection of specimens from patients with communicable diseases Blood, urine, stool, sputum

3. Transportation of specimens Labeling, packaging, delivery to appropriate lab

4. Preparation of specimens Centrifugation, separation, decantation

5. Use of specimen Pipetting, sterilization

6. Disposal of specimen Disposable equipment, garbage facilities, and collection 
the ventilatory power, $34 \%$ said the filter was not cleaned regularly, and $40 \%$ said fumes from reagents irritated their eyes or nose.

Pipetting practices. Of 559 people who pipetted regularly at their jobs, $82 \%$ pipetted by mouth, at least occasionally, and nearly half had at one time or other had a mouth full of specimen or reagent; $37 \%$ reported that reusable glass pipettes were not autoclaved, and $15 \%$ said that disposable pipettes were routinely reused.

Garbage disposal. One-fourth of the 696 respondents thought garbage cans were not large enough, and 72\%-nearly three-fourths-reported that garbage cans in which lab specimens or containers were discarded had no covers. About $32 \%$ said potentially infectious garbage was not autoclaved, and $42 \%$ said liquid waste and solid waste were thrown out together. Twenty percent reported that used hypodermic needles were tossed out with the rest of the garbage, without being properly destroyed.

Physical examination. Four-hundred and thirteen respondents received an annual physical examination, but only about one-third received their own results directly. Of these exams $84 \%$ included a complete blood count, and $63 \%$ included an SMA-12 blood analysis. Nearly all physicals included urine tests, chest $\mathrm{X}$ rays, and VDRL, while $42 \%$ included an Australian antigen titer.

Hepatitis risks. Forty-six workers, or $7 \%$ of the sample, reported a history of hepatitis, which is the most serious infection associated with hospital laboratory work. We found it instructive to classify these workers by their work practices, thereby estimating relative risks for hepatitis associated with these priorities. For example, the risk for hepatitis among workers who wore their lab uniform to the cafeteria was 2.2 times that of workers who did not. The risk for hepatitis was the same in those who pipetted as in those who did not, but was nearly three times as great $(R R=2.85)$ among those who had ever had solutions in their mouths as those who had not.

\section{DISCUSSION}

The results of the District 1199 laboratory survey can be considered representative of laboratory practices and worker health in many large urban hospitals. Attention was focused in this report on hepatitis, because it is recognized as a serious hazard for medical personnel $(2,4)$. The World Health Organization has estimated that medical and ancillary hospital staff have an incidence of clinical hepatitis infection three to six times greater than that of workers in other occupations (6). A recent epidemiological survey conducted by the Center for Disease Control in a southwestern United States hospital (5) found that both technicians and practical nurses experienced a risk for carrying hepatitis $B$ surface antigen $\left(\mathrm{HB}_{\mathrm{s}} \mathrm{Ag}\right)$ and antibody (anti- $\left.\mathrm{HB}_{\mathrm{s}}\right)$ which was $70 \%$ greater than that of all hospital employees (adjusted for socioeconomic status). This excess risk, which was not experienced by any other occupational group within the hospital, was thought to be related to "the expected high frequency of routine blood exposure, often with no precautionary measures" [Ref. (5), p. 64]. It was specifically highest among workers with frequent assignments in laboratories (risk $=1.6$ ) and operating rooms (risk $=2.4$ ).

Many different types of hospital workers are potentially at risk for intercurrent infectious diseases. These include doctors and nurses, as well as clerks who 
TABLE 2

Employment of Women in Health Professions: Annual Averages-1973“

\begin{tabular}{lccc}
\hline & $\begin{array}{c}\text { Number of women } \\
\left(\times 10^{3}\right)\end{array}$ & $\begin{array}{l}\text { Percentage of } \\
\text { employed women } \\
\text { in this } \\
\text { occupation }\end{array}$ & $\begin{array}{l}\text { Percentage of } \\
\text { persons in this } \\
\text { occupation who } \\
\text { are women }\end{array}$ \\
\hline $\begin{array}{l}\text { Registered nurses } \\
\text { Health technologists } \\
\text { and technicians }\end{array}$ & 805 & 2.5 & 97.8 \\
$\begin{array}{c}\text { Health Service workers } \\
\text { Dental assistants }\end{array}$ & 236 & 0.7 & 71.5 \\
$\begin{array}{c}\text { Health aides and } \\
\text { trainees (exclud- } \\
\text { ing nursing) }\end{array}$ & 1,398 & 4.3 & 87.6 \\
$\quad \begin{array}{l}\text { Nursing aides, } \\
\text { orderlies, and }\end{array}$ & 112 & 0.3 & 98.2 \\
$\quad$ attendants & 150 & 0.5 & 82.4 \\
Practical nurses & & & 83.9 \\
Physicians & 790 & 2.4 & 96.4 \\
\hline
\end{tabular}

"Source: Ref. (7).

handle and label specimens, messengers who transport them to and from labs, and maintenance staff who handle garbage disposal. Table 2 lists various classes of hospital workers, most of whom are women, who experience potential health hazards of the kind described here (7).

\section{SOLUTIONS TO PROBLEMS}

The District 1199 Laboratory Committee and its subcommittee whose initial work motivated this survey have suggested solutions to the problems listed in Table 1. These actions are presented in Table 3. Many of these were endorsed by management and others were referred to the joint committee for discussion and resolution.

The work of the Health and Safety Subcommittee described above has been expanded in several institutions to cover other areas, such as renal dialysis, recovery room, and operating rooms, and any other places within the hospital where employees can participate in controlling and reducing their own job-related health risks. A comparison of the survey results already presented here with the sug-

TABLE 3

Action Suggested by Union Health and Safety Committee

\begin{tabular}{cl}
\hline 1. & $\begin{array}{c}\text { Special in-service education programs for laboratory } \\
\text { workers, stressing careful handling of specimens and reagents } \\
2 .\end{array}$ \\
Automatic pipetting of all biological specimens \\
4. & Sterilization of all reusable glassware \\
5. & Frequent washing of lab floor \\
6. & Footic liners and covers for all garbage cans \\
7. & Employee participation in selection of uniforms \\
\hline
\end{tabular}


gestions given in Table 3, indicates that many of the problem areas described in one hospital are generally found throughout other hospitals in the New York City area.

\section{REFERENCES}

1. Ashford, N. A. "Crisis in the Workplace: Occupational Disease and Injury." MIT Press, Cambridge, 1976.

2. Byrne, E. B. Viral hepatitis: An occupational hazard of medical personnel. JAMA 195, 362364 (1966).

3. Carter, B. J., and Egan, V. S. State's safety plan lowers insurance costs. Mod. Hosp., July (1965).

4. Grist, N. R. Hepatitis in clinical laboratories: A 3-year survey. J. Clin. Pathol. 28, 255-259 (1975).

5. Pattison, C. P., Maynard, J. E., Berquist, K. R., and Webster, H. M. Epidemiology of hepatitis B in hospital personnel. Amer. J. Epidemiol. 101, 59-64 (1975).

6. World Health Organization. "Viral Hepatitis," Technical Report Series, No. 512, p. 35, 1973.

7. U.S. Department of Labor. "1975 Handbook on Women Workers." Bulletin 297, pp. 89-91, 1975. 